\title{
Early sexual maturation, central adiposity and subsequent overweight in late adolescence. A four-year follow-up of 1605 adolescent Norwegian boys and girls: the Young HUNT study
} Grete H Bratberg*1,2,3, Tom IL Nilsen ${ }^{\dagger 2}$, Turid L Holmen ${ }^{\dagger 1}$ and Lars J Vatten ${ }^{\dagger 2}$

Address: ${ }^{1}$ HUNT Research Centre, Faculty of Medicine, Norwegian University of Science and Technology, Verdal, Norway, ${ }^{2}$ Department of Public Health and General Practice, Faculty of Medicine, Norwegian University of Science and Technology, Trondheim, Norway and ${ }^{3}$ Nord-Trøndelag University College, Levanger, Norway

Email: Grete H Bratberg* - grete.bratberg@ntnu.no; Tom IL Nilsen - tom.i.nilsen@ntnu.no; Turid L Holmen - turid.lingaas.holmen@ntnu.no; Lars J Vatten - lars.vatten@ntnu.no

* Corresponding author †Equal contributors

Published: 12 April 2007

BMC Public Health 2007, 7:54 doi: 10.1 I86/147/-2458-7-54
Received: II August 2006

Accepted: 12 April 2007

This article is available from: http://www.biomedcentral.com/I47/ -2458/7/54

(C) 2007 Bratberg et al; licensee BioMed Central Ltd.

This is an Open Access article distributed under the terms of the Creative Commons Attribution License (http://creativecommons.org/licenses/by/2.0), which permits unrestricted use, distribution, and reproduction in any medium, provided the original work is properly cited.

\begin{abstract}
Background: Early sexual maturation has been associated with overweight that may persist after the completion of biological growth and development. We have prospectively examined the influence of early sexual maturation on subsequent overweight in late adolescence and assessed if this association was modified by central adiposity in early adolescence.
\end{abstract}

Methods: 1605 Norwegian adolescents were followed from early (baseline, mean age 14.2 years) to late adolescence (follow-up, mean age 18.2 years). Maturational timing was assessed by selfreports of pubertal status (PDS) in boys and age at menarche (AAM) in girls. Central adiposity was classified according to waist circumference (waist) measured at baseline, using age and gender specific medians as cut off. Overweight was classified according to International Obesity Task Force (IOTF) standards.

Results: At follow-up, early sexual maturation in girls, but not in boys, was associated with overweight. This association, however, was restricted to girls with high waist circumference (> median) at baseline (OR, 2.7, 95\% Cl 1.5-4.9). Thus, age at menarche was not associated with overweight in girls with low waist ( $\leq$ median) at baseline. Central adiposity was, independent of maturational timing, associated with higher BMI at follow-up in both genders, but differences were more pronounced among early matured girls $\left(3.5 \mathrm{~kg} / \mathrm{m}^{2}\right)$, than among intermediate $\left(2.7 \mathrm{~kg} / \mathrm{m}^{2}\right)$ and late matured girls $\left(1.2 \mathrm{~kg} / \mathrm{m}^{2}\right)$.

Conclusion: In girls, the combination of central adiposity and early age at menarche appears to increase the risk of being overweight in late adolescence.

\section{Background}

The global increase in overweight and obesity at a young age [1] has alarming prospects, due to its long-term association with the risk of cardiovascular disease and diabetes as well as other chronic diseases [2,3]. Since the amount of body fat increases secondary to pubertal development, adolescence may be a critical period for developing overweight [4]. 
Studies have shown that those who mature early or more rapidly have higher body-mass index (BMI) and are at greater risk of developing overweight in adolescence and also in adulthood [5-9]. Those who mature early also tend to have more of their subcutaneous fat on the trunk than same aged others $[6,10]$. The latter observation may be particularly important because central fat may be a greater threat to health than peripheral fat [11].

The biological mechanisms underlying the association between early maturation and overweight are still unclear, but since overweight children tend to undergo their sexual maturation earlier than leaner children [12], subsequent overweight has been attributed to over-nutrition in childhood [13-15]. The joint effect of early sexual maturation and early adiposity may be central for the development of overweight $[13,15]$. Others have suggested that the association between early sexual maturation and adult obesity is independent of nutritional status at an early age [8]. It is, however, difficult to isolate the effects of early adiposity from the effects of early maturation. One common problem has been the reliance on body-mass index (BMI) as indicator of body fatness, which in young people may reflect maturational status as well as fatness [16,17]. Overweight is therefore suggested to be overestimated among those who mature early [13].

The aim of this study was to examine whether the association between the timing of sexual maturation and subsequent fatness (i.e. BMI and overweight) in late adolescence was modified by boys' and girls' level of central adiposity (i.e. waist circumference) as assessed in early adolescence.

\section{Methods \\ Materials}

This is a prospective study of 1605 adolescent students (the Young-HUNT Study) in Nord-Trøndelag County in Norway, who was examined twice with four years apart. The baseline study was conducted in middle school (age 12-16 years) between August 1995 and June 1997 (baseline). The Young HUNT 2 study (follow-up) took place between January 2000 and June 2001, when the students were in $12^{\text {th }}$ or $13^{\text {th }}$ grade in high school (age 16-20 years). The overall attendance was 95\% at baseline and $86 \%$ at follow-up. The baseline and follow-up study were performed with identical and standardized procedures. Within a month after completing a self-administered questionnaire the students underwent clinical examinations, including measurements of height, weight, and waist and hip circumference. Among the 1605 participants with clinical assessments, 697 boys and 864 girls with registered information about maturational timing were eligible for analyses.

\section{Measurements}

Self-reports of pubertal status in boys and age at menarche in girls were used to indicate timing of sexual maturation. We classified each individual as early or late relative to intermediate maturing boys and girls of the same age. At baseline, boys were asked to assess changes in secondary sexual characteristics by use of the Pubertal Developmental Scale (PDS). The PDS was originally developed by Petersen et al, and has later been validated [18,19]. In our study, reliability tests showed good internal consistency between the reported characteristics of sexual maturation ( $\alpha=0.85$ ). The boys rated themselves according to growth spurt and pubic hair growth; and were asked to assess changes in voice and facial hair growth. On a scale ranging from 1 (have not begun) to 4 (development completed) they were asked to report the extent of pubertal changes. Total score for the four items was summarized and divided by 4 , in order to maintain the original range from 1 to 4 . Stratified by age, we classified boys who had PDS score in the lowest quintile as "late" matured, and those who were in the highest quintile as "early" matured. Those who scored between these extremes were classified as "intermediate" (Table 1).

At baseline, girls were asked to report their age at menarche (AAM) in years and months. Reliability of selfreported AAM is well established [20]. One fifth of the responders had not yet reached menarche $(n=158)$, or had incomplete or missing data $(n=30)$. For these girls we relied on information on AAM collected at follow-up. Mean AAM was 13.2 years $(\mathrm{SD}=1.2)$. We classified girls whose menarche occurred before 12.5 years $(20 \%)$ as "early" matured, girls with AAM between 12.5-13.9 years $(60 \%)$ were classified as "intermediate", and girls with AAM at 14.0 years or later $(20 \%)$ as "late" (Table 1 ).

Anthropometry was measured with the participants wearing light clothes and no shoes. Height and waist circumference was read to the nearest centimetre $(\mathrm{cm})$ and weight to the nearest half kilogram $(\mathrm{kg})$. We used waist circumference, as assessed at baseline as indicator of level of central adiposity (Table 1). Participants with waist circumference above the median within each gender and age group (i.e. half-year groups) were classified as having "high waist" and those below or at the median, were classified as having "low waist". Validation studies have shown high correlation between waist circumference and trunk fat measured by DEXA- scan, that measures both fat and lean body mass, among 3-19 years old children and adolescents [21,22].

As outcome, we used BMI and overweight as registered at follow-up in late adolescence. Body-mass index (BMI) was calculated as weight in kilograms divided by the squared value of height in meters $\left(\mathrm{kg} / \mathrm{m}^{2}\right)$. Overweight 
Table I: Characteristics of the study cohort at baseline

\begin{tabular}{|c|c|c|c|c|}
\hline \multirow[b]{2}{*}{ Characteristics } & \multirow[b]{2}{*}{ Gender } & \multicolumn{3}{|c|}{ Timing of sexual maturation } \\
\hline & & Early & Intermediate & Late \\
\hline \multirow[t]{2}{*}{ Age, mean $(95 \% \mathrm{Cl})$} & boys & |4.3 (|4.2-|4.5) & |4.2(|4.|-|4.3) & $14.0(|3.9-| 4.1)$ \\
\hline & girls & $14.2(|4|-.\mid 4.3)$ & $14.3(\mid 4.2-14.4)$ & $14.2(\mid 4.1-14.3)$ \\
\hline Pubertal status (PDS), mean score $(95 \% \mathrm{Cl})^{\mathrm{a}}$ & boys & $3.1(3.1-3.2)$ & $2.4(2.4-2.4)$ & $1.7(1.6-1.7)$ \\
\hline Age at menarche, mean years $(95 \% \mathrm{Cl})$ & girls & $11.7(11.6-11.8)$ & $13.1(13.0-13.1)$ & $14.8(\mid 4.7-14.9)$ \\
\hline \multirow[t]{2}{*}{ Waist circumference, mean a $(95 \% \mathrm{Cl})$} & boys & $73.6(72.4-74.7)$ & $72.1(71.3-72.8)$ & $69.8(68.7-70.9)$ \\
\hline & girls & $68.4(67.4-69.5)$ & $68.6(67.9-69.2)$ & $65.8(64.8-66.8)$ \\
\hline \multirow[t]{2}{*}{ Body mass index, mean a $(95 \% \mathrm{Cl})$} & boys & $20.7(20.3-21.1)$ & $19.9(19.6-20.2)$ & $19.2(18.8-19.7)$ \\
\hline & girls & $21.1(20.7-21.5)$ & $20.6(20.3-20.8)$ & $18.9(18.5-19.3)$ \\
\hline
\end{tabular}

a Age-adjusted means

was classified according to The International Obesity Task Force (IOTF) standards, which link BMI percentiles during childhood and adolescence to the widely used adult cutoff-points of $25 \mathrm{~kg} / \mathrm{m}^{2}$ at age 18 , as a definition of overweight [23].

\section{Ethics}

Participation was voluntary and each student signed a written statement of consent. For students younger than 16 years of age, we also obtained written consent from their parents. The Young HUNT study was approved by the Regional committee for ethics in medical research, and by the Norwegian Data Inspectorate.

\section{Statistics}

We examined the independent and modifying effect of early central adiposity (i.e. waist circumference $>$ median) on the association between timing of sexual maturation and subsequent fatness (i.e. overweight and BMI) by multivariate logistic analyses and linear regression analyses, and by stratification. Logarithmic (ln) transformation of BMI at follow-up was used to fit model assumptions in linear regression analyses. Logistic regression analysis was used to study the association between timing of sexual maturation and prevalence of overweight at follow-up, in groups characterised by high ( $>$ median) or low ( $\leq$ median) waist circumference at baseline, adjusting for potential confounding of age, waist circumference, parental education level, frequency of leisure time physical activity, and frequency of intake of sweets and soft drinks as reported at baseline. We used a general linear model to compute multivariate adjusted mean BMI and mean differences in BMI at follow-up, conducted separately for early, intermediate and late matured boys and girls, adjusting for the potential confounding of age, parental education level, frequency of leisure time physical activity and of intake of sweets and soft drinks as reported at base- line. Precision of the estimates was assessed with 95\% confidence intervals (CI) and all reported $P$-values are two-sided. All statistical analyses were performed using SPSS for Windows, version 13 (SPSS, Chicago, USA).

\section{Results \\ Baseline characteristics}

At baseline, pubertal status in boys and age at menarche in girls differed significantly between individuals classified as early, intermediate and late (Table 1). Age adjusted mean waist circumference (Table 1) was higher in early $(73.6 \mathrm{~cm})$ maturing boys, compared to boys who were intermediate $(72.1 \mathrm{~cm})(P$-value $=.03)$ or late matured $(69.8 \mathrm{~cm})(P$-value <.001). Waist circumference did not differ significantly between early $(68.4 \mathrm{~cm})$ and intermediate $(68.6 \mathrm{~cm})$ maturing girls, whereas late maturing girls on average were leaner $(65.8 \mathrm{~cm})(P$-value $<.001)$ than intermediate matured girls. Age adjusted mean BMI at baseline differed significantly between all timing categories and was highest among early maturing boys $(20.7 \mathrm{~kg} /$ $\left.\mathrm{m}^{2}\right)$ and girls $\left(21.1 \mathrm{~kg} / \mathrm{m}^{2}\right)$ and lowest among late maturing boys $\left(19.2 \mathrm{~kg} / \mathrm{m}^{2}\right)$ and girls $\left(18.9 \mathrm{~kg} / \mathrm{m}^{2}\right)$.

\section{Tracking of adiposity from baseline to follow-up}

During follow-up, mean BMI increased by more than 2 $\mathrm{kg} / \mathrm{m}^{2}$ and in late adolescence, overweight was more common in all timing categories than at baseline, except for boys with late sexual maturation. Among those classified as overweight at baseline, $80 \%$ of boys and $70 \%$ of girls were also classified as overweight at follow-up (data not shown).

\section{The prevalence of overweight at follow up}

At follow-up, $20 \%$ of boys and 19\% of girls were classified as overweight. Overweight was more than twice as common among early matured boys and girls (26\%), compared to boys $(11 \%)$ and girls $(10 \%)$ who had matured 
late. After adjustment for age, parental education level, frequency of leisure time physical activity and frequency of intake of sweets and soft drinks as reported at baseline, early maturing girls, but not boys, were slightly more likely (OR, 1.6, 95\% CI $1.0-2.5)$ to be overweight, compared to girls who were intermediate matured $(P$-value $=$ $.03)$. Late matured boys (OR, 0.5, 95\% CI 0.3-0.9) and girls (OR, $0.5,95 \%$ CI $0.3-0.8$ ) were both less likely to be overweight compared to intermediate matured counterparts.

\section{The modifying influence of waist circumference}

We studied whether the association between timing of sexual maturation and overweight at follow-up could be modified by level of central adiposity at baseline (indicated by waist circumference). The results showed that for girls, but not for boys, there was a statistically significant interaction between timing categories and baseline waist circumference $(P$-value $=.006)$. Further stratified analysis showed that among girls with low waist circumference ( $\leq$ median), early AAM was not associated with subsequent overweight at follow-up (Table 2). Among girls with high waist (> median), early matured girls were 2.7 times as likely (95\% CI $1.5-4.9)$ to be overweight, compared to intermediate matured girls within this group. Odds ratios were adjusted for age, waist circumference, parental education level, physical activity and intake of soft drinks and sweets as obtained at baseline (Table 2).

By use of linear regression analyses, we estimated the independent and combined influence of timing of sexual maturation and waist circumference on mean BMI at follow-up. In boys (Table 3 ), both pubertal status score $(P$ value $=.005)$ and waist circumference $(P$-value $<.000)$ at baseline (age-adjusted), contributed independently to BMI at follow-up (Model 1), but the interaction term was not statistically significant (Model 2). In girls, age at menarche $(P$-value $=.002)$ and waist circumference $(P$ value $<.000)$ were both independently related to BMI (Model 1), but in girls these effects were interactive (Model 2, P-value $=.002$ ). Inclusion of the interaction term, however, did not change the adjusted $\mathrm{R}^{2}$ (Table 3 ).

Further stratified analyses showed that across all maturational timing groups, mean BMI at follow-up was significantly higher among boys and girls with high waist circumference ( $>$ median), compared to those with low circumference $(\leq$ median) at baseline (Table 4$)$. In girls, however, differences appeared to be more pronounced among those with early age at menarche $\left(3.5 \mathrm{~kg} / \mathrm{m}^{2}, 95 \%\right.$ CI 1.7-5.3) than among intermediate $\left(2.7 \mathrm{~kg} / \mathrm{m}^{2}, 95 \%\right.$ CI $1.8-3.6)$ and late matured girls $\left(1.2 \mathrm{~kg} / \mathrm{m}^{2}, 95 \%\right.$ CI $0.1-$ 2.2). Differences in age and height adjusted weight at follow-up, showed that early matured girls with high waist circumference at baseline ( $>$ median) weighed on average
$11.2 \mathrm{~kg}$ more than those with low waist $(\leq$ median) $(P$ value <.001) (data not shown).

\section{Discussion}

In this prospective study of boys and girls we found that early age at menarche in girls was associated with overweight in late adolescence, but the association was only present in girls with relatively high central adiposity at baseline (waist circumference above the median).

Longitudinal studies have shown that differences in BMI and body fatness related to sexual maturation may persist, also after the completion of biological growth and development $[7,10,24-26]$. Some previous cross-sectional studies have reported a relatively strong association between early sexual maturation and overweight in girls $[5,8,9]$, but limited research has been conducted in boys. Since sexual maturation tends to occur earlier in overweight children, it has been suggested that early adiposity may play an important role for subsequent fatness. However, it is not easy to single out the independent influence of early sexual maturation on this association. In women, it was recently reported that nearly all the influence of early menarche on adult overweight could be attributed to childhood adiposity [15]. Other studies have shown that the influence of early age at menarche on adult obesity could be mediated by childhood adiposity, but that the whole effect could not be explained by this $[13,14]$. In our study, we found that early menarche was not associated with overweight in girls that were relatively lean at the entry of the study, i.e. in early adolescence.

Many factors may contribute to early menarche, and genetic make up is probably influential for the timing of all pubertal milestones. The onset of puberty may also represent a sensitive early marker of interactions between environmental conditions and genetic susceptibility [27]. The single most important environmental factor is childhood over-nutrition that may have profound effects on the tempo of growth and puberty $[28,29]$. Thus, the influence of childhood adiposity on subsequent timing of puberty has been observed in very young children $[12,30,31]$. Given that the timing of puberty is triggered by childhood over-nutrition, obese children who mature early may differ from other early maturing children in many respects. In another study conducted on this population, we found that early maturation combined with early central adiposity was associated with normal final height, while early maturation combined with "leanness" at a young age was associated with relatively short final stature [32]. These results suggest that differences in stature and fatness in late adolescence that could be linked to early central adiposity were more pronounced among those who matured early compared to those who matured later, and this pattern was especially apparent in girls. Pre- 
Table 2: Odds ratio (OR) of being classified as overweight a at follow-up in late adolescence associated with timing of sexual maturation stratified by level of central adiposity (i.e. waist circumference)

\begin{tabular}{|c|c|c|c|c|c|c|c|c|c|c|}
\hline \multirow[b]{2}{*}{ Timing } & \multicolumn{5}{|c|}{ High waist circumference (> median) } & \multicolumn{5}{|c|}{ Low waist circumference ( $\leq$ median) } \\
\hline & Overweight ${ }^{\mathrm{a}}$ & Normal weight & $\mathrm{OR}^{\mathrm{b}}$ & $\mathrm{OR}^{\mathrm{c}}$ & $95 \% \mathrm{Cl}$ & Overweight ${ }^{\mathrm{a}}$ & Normal weight & $\mathrm{OR}^{\mathrm{b}}$ & $\mathrm{ORc}^{\mathrm{c}}$ & $95 \% \mathrm{Cl}$ \\
\hline \multicolumn{11}{|l|}{ Boys } \\
\hline Early & 37 & 66 & 0.9 & 1.0 & $0.6-1.9$ & 7 & 56 & 2.4 & 0.9 & $0.2-4.2$ \\
\hline Intermediate & 62 & 105 & 1.0 & 1.0 & Reference & 9 & 172 & 1.0 & 1.0 & Reference \\
\hline Late & 19 & 35 & 0.9 & 0.8 & $0.3-1.7$ & 0 & 110 & NC & NC & - \\
\hline \multicolumn{11}{|l|}{ Girls } \\
\hline Early & 42 & 50 & 1.8 & 2.7 & $1.5-4.9$ & 2 & 81 & 0.5 & 0.5 & $0.1-2.7$ \\
\hline Intermediate & 78 & 164 & 1.0 & 1.0 & Reference & 11 & 220 & 1.0 & 1.0 & Reference \\
\hline Late & 10 & 52 & 0.4 & 0.3 & $0.1-0.9$ & 8 & 115 & 1.4 & 2.2 & $0.8-6.2$ \\
\hline
\end{tabular}

a Classified according to the International Obesity Task Force (IOTF) percentile cut-off points for children and adolescents, b Unadjusted OR, cAdjusted for baseline age, waist circumference, dietary sugar intake, leisure time physical activity and parental education level, $\mathrm{Cl}$ denotes confidence interval and NC denotes not calculated

vious studies have reported a joint effect between childhood BMI and age at menarche on adult BMI $[13,15]$, but the heterogeneity in effect related to early sexual maturation has to our knowledge not previously been described.

Adolescence may be a critical period for developing overweight [4], but results have also indicated that the major part of early adiposity may be fully developed by 11 years of age, or earlier [33]. Although we found that the overall prevalence of overweight increased gradually from early to late adolescence, nearly all participants who were overweight at follow-up had central adiposity at baseline. Among those with central adiposity above the median, however, early maturing girls were nearly three times as likely to be classified as overweight at follow-up as intermediate matured girls.

Even if waist circumference percentile charts have been described [34], appropriate cut-off points for defining overweight have not yet been identified. Compared to British adolescents for example, participants in this study
(1995-97) were on average "leaner" than adolescents in a British study from 1997, but "fatter" than the British were before 1990 [34]. This may reflect country specific increases in adolescent body size over the last few decades. About half the girls with early age at menarche in our study were relatively lean at baseline (indicated by waist circumference) and remained lean at follow-up. This appears to be in contrast to the findings of Must et al, who found that the leanest girls had not experienced early age at menarche [15]. In that study, however, the definition of leanness was more stringent, and early adiposity was accounted for by the use of BMI and not waist circumference, as in our study.

Possible health risks associated with high waist circumference may not be clear, but this measure has been recommended in studies of children and adolescents [1]. Studies have shown that waist circumference has increased in children and adolescents since the 1990s, and appears to exceed the corresponding increase in BMI [34]. Compared to the use of BMI, waist circumference has shown to be

Table 3: The independent and combined influence of timing of sexual maturation (SM timinga) and waist circumference on logtransformed mean BMI at follow-up, reported as standardised beta coefficients ${ }^{b}$

\begin{tabular}{|c|c|c|c|c|c|c|c|c|}
\hline \multirow[t]{3}{*}{ Independent variables } & \multicolumn{4}{|c|}{ Boys } & \multicolumn{4}{|c|}{ Girls } \\
\hline & \multicolumn{2}{|c|}{ Model I } & \multicolumn{2}{|c|}{ Model 2} & \multicolumn{2}{|c|}{ Model I } & \multicolumn{2}{|c|}{ Model 2} \\
\hline & $\beta$ & $P$-value & $\beta$ & $P$-value & $\beta$ & $P$-value & $\beta$ & $P$-value \\
\hline SM timing ${ }^{a}$ & 0.09 & $<.000$ & 0.12 & .65 & -0.09 & .002 & 0.68 & .006 \\
\hline Waist circumference & 0.68 & .005 & 0.69 & $<.000$ & 0.60 & $<.000$ & 1.53 & $<.000$ \\
\hline SM timing*waist circumference & & & -0.03 & .92 & & & -1.11 & .002 \\
\hline Model, adjusted $R^{2}$ & \multicolumn{2}{|c|}{0.48} & \multicolumn{2}{|c|}{0.48} & \multicolumn{2}{|c|}{0.39} & \multicolumn{2}{|c|}{0.39} \\
\hline
\end{tabular}

a SM timing denotes pubertal status in boys and age at menarche in girls, both included as continuous variables in analyses

b Coefficients are adjusted for age at baseline. 
Table 4: Mean BMI $\left(\mathrm{kg} / \mathrm{m}^{2}\right)$ at follow-up related to level of central adiposity (i.e. waist circumference) at baseline, stratified by timing of sexual maturation (SM timing) and gender

\begin{tabular}{|c|c|c|c|c|c|c|}
\hline \multirow[b]{2}{*}{ SM timing } & \multicolumn{2}{|c|}{ High waist circumference (> median) } & \multicolumn{2}{|c|}{ Low waist circumference ( $\leq$ median) } & \multirow[b]{2}{*}{ Mean a difference $(95 \% \mathrm{Cl})$} & \multirow[b]{2}{*}{ P-value } \\
\hline & No. of participants & Mean a BMI $(95 \% \mathrm{Cl})$ & No. of participants & Mean a BMI $(95 \% \mathrm{Cl})$ & & \\
\hline \multicolumn{7}{|l|}{ Boys } \\
\hline Early & 103 & $24.7(23.7-25.6)$ & 60 & $21.8(20.7-22.9)$ & $2.9(1.4-4.4)$ & $<.001$ \\
\hline Intermediate & 167 & $24.9(24.1-25.7)$ & 180 & $21.5(20.7-22.3)$ & $3.4(2.3-4.5)$ & $<.001$ \\
\hline Late & 52 & $23.8(22.5-25.1)$ & 109 & $20.5(19.5-21.5)$ & $3.3(1.6-4.9)$ & $<.001$ \\
\hline \multicolumn{7}{|l|}{ Girls } \\
\hline Early & 89 & $24.7(23.4-25.9)$ & 83 & $21.2(19.9-22.4)$ & $3.5(1.7-5.3)$ & $<.001$ \\
\hline Intermediate & 236 & $24.0(23.4-24.6)$ & 224 & $21.3(20.7-22.0)$ & $2.7(1.8-3.6)$ & $<.001$ \\
\hline Late & 58 & $22.2(21.3-23.0)$ & 121 & $21.0(20.3-21.7)$ & $1.2(0.1-2.2)$ & .04 \\
\hline
\end{tabular}

a Means, adjusted for age at follow-up and dietary sugar intake, leisure time physical activity and parental education reported at baseline, $\mathrm{Cl}$ denotes confidence interval

less affected by gender, race and pubertal maturation $[21,35]$. In our study, mean waist circumference did not differ significantly between early and intermediate matured girls at baseline, but was slightly lower among late maturing girls. Early maturing boys, however, were less likely to be classified as lean and thus, central adiposity may be overestimated in this group. Our study revealed quite different results for boys and girls, especially in relation to central adiposity. Due to the gender dimorphism in fat deposition [21] and since the typical adult fat distribution is gained at an older age in boys than in girls [36], gender comparisons may not be appropriate. Different indicators of sexual maturation were also considered for boys and girls and could explain some of the discrepancies in findings. Others, however, have also reported gender differences related to early sexual maturation and overweight [9], which may involve both genetic as well as endocrine factors.

There are several limitations associated with the use of self-reports of pubertal events. Short-term-recalls of AAM, however, is considered reliable [20], and has been extensively used in epidemiological studies. Validation studies have also shown moderate to good agreement between self-evaluations and physicians' ratings of sexual maturation, but ratings may be overestimated in early stages of puberty and in obese children [19,37-39]. In our data there was high consistency between self-reports of pubertal status and clinically obtained height and weight measurements at baseline. Another limitation was that we had no access to childhood growth data and thus, we were not able to study the possible link between childhood overnutrition, age at onset of puberty and subsequent fatness during adolescence.
Main strengths of our study include the longitudinal design, its high attendance, and the use of standardised anthropometric measurements. Due to Caucasian homogeneity, ethnic origin is unlikely to explain the observed variation in maturation and body composition in this population.

\section{Conclusion}

We found that the increased risk of early maturing girls to be overweight in late adolescence was confined to girls with relatively high central adiposity in early adolescence. Thus, the combination of early adiposity and early age at menarche appears to increase the risk of being overweight in late adolescence.

\section{Competing interests}

The author(s) declare that they have no competing interests.

\section{Authors' contributions}

GHB and LJV contributed significantly in all parts of the research process. TLH was responsible for the data collection and administration of the Young HUNT study. TILN contributed in statistical analysis and in interpretation of results. All co-authors critically reviewed the process and provided suggestions for manuscript revisions. They have all read and approved the final manuscript.

\section{Acknowledgements}

The Young-HUNT Study is a collaboration between HUNT Research Centre, Faculty of Medicine, The Norwegian University of Science and Technology (NTNU), The Norwegian Institute of Public Health, and The NordTrøndelag County Council. We thank the Norwegian Research Council for financial support. 


\section{References}

I. Lobstein T, Baur L, Uauy R: Obesity in children and young people: a crisis in public health. Obes Rev 2004, 5 Suppl I:4- I04.

2. Dietz WH: Health consequences of obesity in youth: childhood predictors of adult disease. Pediatrics 1998, I 0 I:5 I 8-525.

3. Katzmarzyk PT, Tremblay A, Perusse L, Despres JP, Bouchard C: The utility of the international child and adolescent overweight guidelines for predicting coronary heart disease risk factors. j Clin Epidemiol 2003, 56:456-462.

4. Dietz WH: Periods of risk in childhood for the development of adult obesity--what do we need to learn? J Nutr 1997, I 27: I884S-1886S.

5. Adair LS, Gordon-Larsen P: Maturational timing and overweight prevalence in US adolescent girls. Am J Public Health 200I, 9l:642-644.

6. Beunen G, Malina RM, Lefevre J, Claessens AL, Renson R, Simons J, Maes $H$, Vanreusel $B$, Lysens $R$ : Size, fatness and relative fat distribution of males of contrasting maturity status during adolescence and as adults. Int J Obes Relat Metab Disord 1994, I 8:670-678

7. Biro FM, McMahon RP, Striegel-Moore R, Crawford PB, Obarzanek E, Morrison JA, Barton BA, Falkner F: Impact of timing of puberta maturation on growth in black and white female adolescents: The National Heart, Lung, and Blood Institute Growth and Health Study. J Pediatr 200I, I38:636-643.

8. Garn SM, LaVelle M, Rosenberg KR, Hawthorne VM: Maturational timing as a factor in female fatness and obesity. Am J Clin Nutr 1986, 43:879-883.

9. Wang Y: Is Obesity Associated With Early Sexual Maturation? A Comparison of the Association in American Boys Versus Girls. Pediatrics 2002, I I 0:903-910.

10. van Lenthe FJ, Kemper HC, van Mechelen W, Post GB, Twisk JW, Welten DC, Snel J: Biological maturation and the distribution of subcutaneous fat from adolescence into adulthood: the Amsterdam Growth and Health Study. Int J Obes Relat Metab Disord 1996, 20:121-129.

II. Freedman DS, Serdula MK, Srinivasan SR, Berenson GS: Relation of circumferences and skinfold thicknesses to lipid and insulin concentrations in children and adolescents: the Bogalusa Heart Study. Am J Clin Nutr 1999, 69:308-317.

12. Davison KK, Susman EJ, Birch LL: Percent body fat at age 5 predicts earlier pubertal development among girls at age 9. Pediatrics 2003, I I I:8I5-82I.

13. Freedman DS, Khan LK, Serdula MK, Dietz WH, Srinivasan SR, Berenson GS: The relation of menarcheal age to obesity in childhood and adulthood: the Bogalusa heart study. BMC Pediatr 2003, 3:3.

14. Power C, Lake JK, Cole TJ: Body mass index and height from childhood to adulthood in the 1958 British born cohort. Am J Clin Nutr 1997, 66:1094-I I0I.

15. Must A, Naumova EN, Phillips SM, Blum M, wson-Hughes B, Rand WM: Childhood overweight and maturational timing in the development of adult overweight and fatness: the Newton Girls Study and its follow-up. Pediatrics 2005, I | 6:620-627.

16. Daniels SR, Khoury PR, Morrison JA: The utility of body mass index as a measure of body fatness in children and adolescents: differences by race and gender. Pediatrics 1997, 99:804-807

17. Wang Y, Adair L: How does maturity adjustment influence the estimates of overweight prevalence in adolescents from different countries using an international reference? Int J Obes Relat Metab Disord 200I, 25:550-558.

18. Brooks-Gunn J, Warren MP, Rosso J, Gargiulo J: Validity of selfreport measures of girls' pubertal status. Child Dev 1987, 58:829-84I.

19. Petersen AC, Crockett L, Richards M, Boxer A: A Self-Report Measure of Pubertal Status - Reliability, Validity, and Initial Norms. Journal of Youth and Adolescence 1988, I 7:1 17-133.

20. Koo MM, Rohan TE: Accuracy of short-term recall of age at menarche. Ann Hum Biol 1997, 24:6I-64.

21. Daniels SR, Khoury PR, Morrison JA: Utility of different measures of body fat distribution in children and adolescents. Am J Epidemiol 2000, I52: I I79-1 I84.

22. Goran MI, Gower BA, Treuth M, Nagy TR: Prediction of intraabdominal and subcutaneous abdominal adipose tissue in healthy pre-pubertal children. Int J Obes Relat Metab Disord I998, 22:549-558.

23. Cole TJ, Bellizzi MC, Flegal KM, Dietz WH: Establishing a standard definition for child overweight and obesity worldwide: international survey. BMJ 2000, 320: I240-I 243.

24. Beunen GP, Malina RM, Lefevre JA, Claessens AL, Renson R, Vanreusel B: Adiposity and biological maturity in girls 6-16 years of age. Int J Obes Relat Metab Disord 1994, I 8:542-546.

25. Guo SS, Chumlea WC, Roche AF, Siervogel RM: Age- and maturity-related changes in body composition during adolescence into adulthood: the Fels Longitudinal Study. Int J Obes Relat Metab Disord 1997, 21:1167-1175.

26. van Lenthe FJ, Kemper CG, van Mechelen W: Rapid maturation in adolescence results in greater obesity in adulthood: the Amsterdam Growth and Health Study. Am J Clin Nutr 1996, 64:18-24.

27. Parent AS, Teilmann G, Juul A, Skakkebaek NE, Toppari J, Bourguignon JP: The timing of normal puberty and the age limits of sexual precocity: variations around the world, secular trends, and changes after migration. Endocr Rev 2003, 24:668-693.

28. Dunger DB, Ahmed ML, Ong KK: Effects of obesity on growth and puberty. Best Pract Res Clin Endocrinol Metab 2005, 19:375-390.

29. Karlberg J: Secular trends in pubertal development. Horm Res 2002, 57 Suppl 2:19-30.

30. He Q, Karlberg J: Bmi in childhood and its association with height gain, timing of puberty, and final height. Pediatr Res 2001, 49:244-25l.

31. Kaplowitz PB, Slora EJ, Wasserman RC, Pedlow SE, Herman-Giddens $M E$ : Earlier onset of puberty in girls: relation to increased body mass index and race. Pediatrics 200I, I 08:347-353.

32. Bratberg GH, Nilsen TI, Holmen TL, Vatten LJ: Combined influence of early sexual maturation and central adiposity on subsequent stature : A four-year follow-up of I,605 Norwegian boys and girls: the Young-HUNT study. Eur J Pediatr 2006, 1 65:787-793.

33. Wardle J, Brodersen NH, Cole TJ, Jarvis MJ, Boniface DR: Development of adiposity in adolescence: five year longitudinal study of an ethnically and socioeconomically diverse sample of young people in Britain. BM/ 2006, 332: | | 30- | | 35.

34. McCarthy HD, Ellis SM, Cole TJ: Central overweight and obesity in British youth aged I I- I6 years: cross sectional surveys of waist circumference. BMJ 2003, 326:624.

35. Pouliot MC, Despres JP, Lemieux S, Moorjani S, Bouchard C, Tremblay A, Nadeau A, Lupien PJ: Waist circumference and abdominal sagittal diameter: best simple anthropometric indexes of abdominal visceral adipose tissue accumulation and related cardiovascular risk in men and women. Am J Cardiol 1994, 73:460-468.

36. Schaefer F, Georgi M, Wuhl E, Scharer K: Body mass index and percentage fat mass in healthy German schoolchildren and adolescents. Int J Obes Relat Metab Disord I998, 22:46 I-469.

37. Bonat S, Pathomvanich A, Keil MF, Field AE, Yanovski JA: Selfassessment of pubertal stage in overweight children. Pediatrics 2002, I I 0:743-747.

38. Schlossberger NM, Turner RA, Irwin CE Jr.: Validity of self-report of pubertal maturation in early adolescents. J Adolesc Health 1992, I 3:109-II3.

39. Williams RL, Cheyne KL, Houtkooper LK, Lohman TG: Adolescent self-assessment of sexual maturation. Effects of fatness classification and actual sexual maturation stage. J Adolesc Health Care 1988, 9:480-482.

\section{Pre-publication history}

The pre-publication history for this paper can be accessed here:

http://www.biomedcentral.com/1471-2458/7/54/prepub 